\title{
l'ÉVOLUTION DU MARIAGE DANS LA PENSÉE DE L'ÉGLISE LE MARIAGE AU MOYEN ÂGE
}

Pour faciliter la compréhension de ce qu'a été le Moyen Âge, situons-le entre l'Antiquité et les temps modernes (i. e., entre Constantin [d. 337] et la Renaissance [XVe siècle] ).

Les personnes qui vivent à cette période mettent Dieu au centre de leur vie. Dieu est l'élément le plus important de leur existence. Il imprègne toutes leurs activités, qu'elles soient religieuses ou politiques. Une telle union avec Dieu dans tous les aspects de la vie se dit théocentrique (Dieu au centre de...). Ce théocentrisme a un impact considérable sur la réalité et la structuration de la vie dans le monde. Il a comme effet le besoin de créer des habitudes personnelles parfaites dans le domaine religieux, à l'image idéalisée de ce qu'est un ascète ou un saint, ou dans le domaine profane, de ce qu'est une figure héroïque comme un chevalier, un roi, etc. Le résultat de cette idéalisation est la subordination de toutes les activités humaines à la religion et sa conception de ce qu'est Dieu.

À cette époque médiévale le dualisme a joué un rôle important. Le dualisme est une pensée religieuse ou philosophique qui reconnaît

* Józef Niesyto OMI jest doktorem nauk teologicznych na Wydziale Teologicznym UMK w Toruniu. Aktualnie pracuje w diecezji Saul Ste. Marie w Kanadzie. 
les opposés dans l'existence originale des choses: le bien et le mal, la matière et l'esprit, le corps et l'âme, le salut et la damnation, le ciel et l'enfer, etc... Cette perception dualiste de la réalité fait que l'homme est confronté par l'obligation d'avoir à choisir entre le désir du bonheur humain et le désir de l'éternité et le ciel. Dans la pensée dualiste, il n'y a pas de juste milieu, de "zone tempérée » pour ainsi dire. Donc, le choix de l'individu est très limité. Il est en présence de deux "extrémités ". Et ce dualisme se manifeste dans un domaine autre que la vie de tous les jours pour les gens de cette époque. L'Église, par la béatification et la canonisation, souligne l'importance de bien choisir entre le bien et le mal, ce qui est, essentiellement, une proposition à caractère dualiste. Tous alors se doivent d'être pieux autant que possible, par respect pour leur foi et en accord avec elle. Le roi et les chevaliers sont obligés de par leurs rôles, d'afficher le courage. Les chrétiens eux cherchent à pratiquer l'ascèse et la mortification. Ils doivent vivre dans la pauvreté et pratiquer la contemplation.

Pour comprendre la mentalité propre à cette époque, rappelons-nous que saint Augustin, reconnu comme une autorité au Moyen Âge, nous a fait comprendre dans un de ses passages qu'il voulait connaître Dieu, mais rien de plus. ${ }^{1}$

Dans l'explication qui suit, nous allons voir comment le mariage était perçu au Moyen Âge, quel rôle la sexualité jouait dans la vie du couple, et par quelles idées et méthodes religieuses le couple était orienté vers la sainteté.

\section{INVITATION À LA SAINTETÉ PERSONNELLE}

Au début du second millénaire, la sainteté personnelle comme idéal, même au sein de la vie conjugale, était exhortée. Cette sainteté s'atteignait par l'exercice de l'abnégation et la continence. La croyance existait déjà que les conjoints n'étaient pas en mesure de donner tout à Dieu s'ils ne s'abandonnaient pas totalement et avec confiance à Lui. Cette vision reposait sur l'idée que l'obligation envers Dieu gardait présence sur les intérêts conjugaux. Les gens de cette époque pensaient que le temps consacré par les conjoints à l'un l'autre et aux autres membres de la famille, était souvent inutile en terme de quête de la sa-

${ }^{1}$ Cf. M. Kaplan, Le Moyen Âge IV $-X^{e}$ sičcles: Histoire médiévale, vol. 1, p. 214. 
inteté. Le temps aurait pu être employé plus salutairement s'il avait été consacré à Dieu. Cette idée s'appliquait aussi au temps que les conjoints consacraient à leurs rapports conjugaux. L'activité affective conjugale, quoi que morale, légitime et permise, demeurait néanmoins suspecte et perçue comme obstructive.

$\mathrm{Au} \mathrm{XIII}^{\mathrm{e}}$ siècle, la vie conjugale a été en quelque sorte réhabilitée dans la pensée de l'Église. Cette dernière invita les conjoints à s'avancer vers la sainteté tout en n'échangeant pas de façon radicale leur vision de leur vie conjugale. L'Église recommande au couple de pratiquer l'abstinence partielle, une tempérance contrôlée, par exemple après la naissance d'un enfant. Dans l'histoire de l'Église, il est possible de trouver plusieurs exemples de couples qui ont tenté l'expérience de cette recommandation.

Il faut souligner que du début du christianisme jusqu'à nos jours, les conjoints ont toujours eu l'option d'entrer en communauté lors du décès de l'autre, surtout si l'abstinence sexuelle avait été rigoureusement pratiquée pendant la vie conjugale. L'époux ou l'épouse alors, de par l'exercice assidu, pour ne pas dire "sacré », devenait modèle de sainteté. La béatification ou la canonisation qui s'en suivait, faisait de lui ou elle un modèle pour la communauté.

L'histoire des saints démontre que l'abstinence sexuelle était pratique courante chez certains d'entre eux lorsqu'ils étaient mariés. Il y va de même dans l'histoire des saintes. Plusieurs d'entre elles avaient été épouses et mères.

La tradition affirme que sainte Kinga $^{2}$ (1292), l'épouse du roi Boleslas le Chaste, a livré une bataille héroïque avec son mari pour conserver la virginité dans leur mariage. Le couple empereur allemand du $\mathrm{X}^{\mathrm{e}}$ et $\mathrm{XI}^{\mathrm{e}}$ siècles, Henri II et Kunegunda, ${ }^{3}$ ont servi d'exemple pour tous les mariages. Ils avaient fait vœu de chasteté et ont été canonisés pour leurs efforts. La bienheureuse Dorothée de Montalban ${ }^{4}$ (1347-1394) a vécu malheureuse avec son mari Adalbert II qui la persécutait à cause de sa foi. Elle pratiquait la prière et le jeûne pour la conversion de son mari. Elle réussit. Après la mort de ce dernier, elle a reçu la permission de se retirer du monde pour entrer volontairement dans une cellule à la cathédrale de Kwidzyn. Sainte Bridget ${ }^{5}$ (1373), contrainte de se marier,

\footnotetext{
2 Cf. Z. Nosowski, Parami do nieba, Warszawa 2010, p. 45.

3 Ibid., p. 63.

4 Ibid., p. 194-195.

${ }^{5}$ Cf. O. Bitschnaua, Żywoty świętych pańskich, Poznań 1894, p. 967-969.
} 
mit au monde huit enfants. Après la mort de son mari, elle fonda un nouvel ordre religieux. Sainte Jadwiga, la reine de Pologne (1374-1399), fut canonisée par le pape Jean-Paul II. Pour des raisons religieuses, politiques et diplomatiques, elle s'est sacrifiée en épousant un homme qu'elle n'aimait pas. $^{6}$

À l'époque médiévale, plusieurs rois, princes et princesses furent canonisés. Mais, lors de la canonisation, on ne soulignait jamais le rôle qu'avait joué le mariage dans leur marche vers la sainteté.

Plus tard, on reconnaît Thomas Moore comme saint. Ce clerc anglais a été martyrisé pour avoir défendu sa foi. Il était un homme marié.

Et que dire de d'autres couples renommés qui ont vécu antérieurement? Sainte Monique, la mère de saint Augustin, a patienté toute sa vie dans la prière pour la conversion de son mari et de son fils. On connaît le résultat. $\mathrm{Au} \mathrm{IV}$ siècle, où le célibat des prêtres n'était pas encore en vigueur, saint Grégoire ${ }^{7}$ et sa femme sainte Nonna, étaient les parents de saint Grégoire de Nazianze, ${ }^{8}$ docteur de l'Église et théologien éminent. À noter qu'il est impossible de fournir un évêque marié comme modèle, parce que le célibat dans l'Église catholique était de rigueur pour les évêques.

Et plus loin encore, au tout début de l'Église naissante, on ne peut oublier Joachim et Anne, ${ }^{9}$ les parents de la Vierge Marie. Que dire de saint Joseph et Marie, les parents de Jésus! Saint Pierre aussi était marié, et probablement les autres apôtres aussi. Le couple chrétien, Aquila et Priscille ${ }^{10}$ ont joué un rôle crucial dans leur collaboration avec saint Paul.

Mais, de part et d'autre, il y eut de l'exagération, issue d'intentions mal conçues, mal informées, mal exprimées et gauchement appliquées.

\section{LA CODIFICATION DE L'ACTE CONJUGAL}

À cette époque l'Église codifiait l'acte conjugal. On y appliquait une réglementation stricte et prescriptive, surtout dans les domaines du temps des relations et de leur fréquence. Le tout risquait de sombrer

\footnotetext{
${ }^{6}$ Ibid., p. 987-991.

${ }^{7}$ Cf. Z. Nosowski, p. 76.

${ }^{8}$ Cf. O. Bitschnaua, p. 476-479.

${ }^{9}$ Ibid., p. 21-23.

${ }^{10}$ Ibid., p. 27-29.
} 
dans le ridicule. Le moine Gratien de Bologne (1140), dans son Décret, une espèce de "corpus contraceptif $d u$ Moyen Âge», écrit ceci: "Le mari devra s'abstenir de sa femme pendant les jours de jeûnes obligatoires, l'avent, le carême, les quatre temps, les vendredis, les vigiles de fêtes. Les couples resteront aussi continents la veille des fętes des principaux saints, en particulier la Vierge Marie, et les dimanches, surtout s'ils reçoivent l'eucharistie... ".11 L'interdit représentait une sentence d'une durée d'environ 185 jours, soit la moitié de l'année. Ce même Gratien était aussi de l'avis que "Ce serait blasphémer le verbe du Seigneur...si la chrétienne, qui en vertu de la loi de Dieu est sujette, voulait commander son mari...La fermme doit, en tout, suivre la décision du mari. Elle n'a aucune autorité; elle ne peut ni enseigner, ni être témoin, ni prêter serment, ni juger.» ${ }^{12}$

Deux croyances vont traverser le Moyen Âge. D'abord celle de la maladie obsessionnelle et culpabilisante. Dans un sermon, Césaire d'Arles (v. 470-543), un saint évęque du début du Moyen Âge, informe les chrétiens : «Bref, tous ceux qui sont lépreux naissent d'ordinaire non pas des hommes savants qui conservent leur chasteté dans les jours contraires et les festivités, mais surtout des rustres qui ne savent se contenir.» ${ }^{13}$

La hantise de la maladie, surtout la peste, prendra le relais au milieu du $\mathrm{XIV}^{\mathrm{e}}$ siècle. On croit que la lèpre reçoit son origine dans la sexualité coupable, y compris celle des époux, surtout celle des époux lorsque la macule de la fornication apparaît à la surface du corps. Et comme la chair transmet le péché originel, les enfants payent la faute des parents. Ensuite, il y a cette fixation de l'excès de dévergondage sexuel dans le monde des "illettrés », des pauvres, et des paysans. Ce n'est pas un hasard si le servage exprime les conséquences du péché originel dans la société chrétienne médiévale. Esclaves de la chair plus que tous les autres, les serfs méritent d'être aussi les esclaves des seigneurs. Dans cette déformation de l'idéal de volontarisme, de résistance, de lutte spirituelle de l'Antiquité tardive, la partie dominée de la société est présentée comme celle des faibles, des abouliques, des êtres sans raison et aussi sans volonté. Dans ce monde de guerriers, les vilains sont des quasi-animaux, jouets du désir mauvais. (Cette incrimination refera surface au milieu du XXe siècle avec des conséquences tragiques à l'échelle mondiale.)

${ }^{11}$ Cf. E. Dufourcq, Histoire des Chrétiennes, Bayard 2008, p. 430.

${ }^{12}$ Ibid.

${ }^{13}$ J. le Goff, L'imaginaire médiéval, France 1985, p. 146; Césaire d'Arles, Sermon XXXIII, 4. Cité in: R. Mac Mullen, Christianisme et paganisme..., p. 246, note 25. 


\section{CATALOGUES DES PÉCHÉS ET DES PÉNITENCES}

$\mathrm{Au}$ début $\mathrm{du} \mathrm{VI}^{\mathrm{e}}$ siècle, dans les monastères médiévaux, l'Église avait établi des catalogues de péchés et de pénitences. Une place spéciale était réservée spécifiquement pour les affaires sexuelles.

Burchard de Worms, un canoniste allemand du $\mathrm{XI}^{\mathrm{e}}$ siècle, héritier de cette tradition, avait aussi écrit un Décret. Dans cet ouvrage à grand retentissement, il écrit à propos de l'abus du mariage : "...Si ta femme est entrée à l'église après l'accouchement avant d'avoir été purifiée de son sang, elle fera pénitence autant de jours qu'elle aurait dû se tenir éloignée de l'église. Et si tu t'es accouplé avec elle ces jours-là, tu feras pénitence au pain et à l'eau pendant vingt jours...T'es-tu accouplé avec ton épouse le jour du Seigneur? Tu dois faire pénitence quatre jours au pain et à l'eau...T'es-tu souillé avec ton épouse en Carême? Tu dois faire pénitence quarante jours au pain et à l'eau, ou donner vingt-six soldes en aumône. Si c'est arrivé pendant que tu étais ivre, tu feras pénitence vingt jours au pain et à l'eau. Tu dois conserver la chasteté vingt jours avant Noël, et tous les dimanches, et pendant tous les jeûnes fixés par la loi, et pour la nativité des apôtres, et pendant les fêtes principales, et dans les lieux publics. Si tu ne l'as pas conservée, tu feras pénitence au pain et à l'eau. $»^{14}$

\section{LA PRÉPARATION DU CÉLIBAT DANS L'ÉGLISE}

La perception du mariage commencée par les Pères de l'Église fut maintenue par les théologiens du Moyen Âge. La vision du mariage occupait toujours la même place dans l'échelle de valeurs : la virginité et l'abstinence sexuelle demeuraient supérieures à l'institution du mariage. Cette préférence pour la chasteté et la privation sexuelle a préparé la voie pour le célibat des prêtres dans l'Église de l'Occident.

Le célibat n'a pas toujours été propre au christianisme. Il existait déjà dans l'Antiquité. L'abstinence était pratiquée par les prêtres païens avant le service au temple. ${ }^{15}$ L'orateur athénien Démosthène (322 av. J.-C.) était de l'opinion qu'il convenait d'observer un certain nombre de jours de continence avant toute visite au temple et tout contact avec des objets sacrés. Un autre nommé Cicéron (106-43 av. J.-C.) écrit:

\footnotetext{
${ }^{14}$ J.-L. Flandrin, Un temps pour embrasser..., Paris 1983, pp. 8-9.

${ }^{15}$ Cf. P. Browe, Zur Geschichte der Entmannung, 1936, p. 13.
} 
"Je vous ordonne de vous tenir loin de l'autel; loin de l'autel quiconque a connu la nuit précédente les joies de l'amour. " ${ }^{16}$ (Encore aujourd'hui, les prêtres païens maintiennent toujours le célibat.) Plutarque (46-120 après. J.-C.), célèbre auteur grec des «Oeuvres morales », faisait la mise en garde contre tout contact sexuel avant la fréquentation du temple et le sacrifice. Une nuit était prescrite comme séparation entre les deux actes. ${ }^{17}$ Dans un temple pad'en de Pergame, une inscription invite les fidèles à un jour de purification après un rapport conjugal et deux jours après un rapport extraconjugal. Cette pratique païenne de l'abstinence sexuelle pour les prêtres qui font service au temple, inspirait l'Église de l'Occident à instituer le célibat pour ses prêtres.

$\mathrm{Au}$ début $\mathrm{du} \mathrm{IV}^{\mathrm{e}}$ siècle, une première étape importante a été franchie dans l'évolution vers le célibat sacerdotal éventuel. Le synode d'Elvira (300-303?) en Espagne prit la décision de proposer que les évêques, les prętres et les diacres mariés pratiquent l'abstinence sexuelle. Cette décision en faveur du célibat n'était pas strictement imposée. Mais elle préparait le terrain pour une réforme permanente du célibat. ${ }^{18}$ La dégradation systématique de l'importance de l'amour physique, et la notion que la soumission à l'abstinence sexuelle et la virginité priment sur l'institution du mariage, ont commencé de plus en plus à jouer un rôle important dans l'établissement du célibat obligatoire. Le mariage et la prêtrise devenaient juridiquement incompatibles après l'ordination. À partir de cette déclaration papale, confirmée par le dernier pape Pie IV (1499-1565), toute union conjugale conclue après le sacrement de l'ordre aurait comme effet d'annuler l'ordination. Le Concile de Trente (1545-1563) rendrait officielle l'impossibilité de l'ordination pour les hommes déjà mariés. Par cette décision, le mariage pour les prêtres fut complètement interdit dans l'Église de 1'Occident. ${ }^{19}$ Mais, le Concile de Trente a aussi décrété que le mariage était exempt de procédure formelle, c'est-à-dire, que l'on pouvait conclure des unions conjugales en secret, et que ces unions étaient valables, sans prêtre ni témoin! (On pourrait, sans trop d'effort, tirer la conclusion que cette concession représentait

${ }^{16}$ M. T. Cicéron, De legibus lib. II r. 8,10. Le pape Pie XI, cite Cicéron dans son encyclique: Ad catholici sacerdotii fastigium, Rome 1935.

${ }^{17}$ L.M. Plutarch, Questions conv. 3,6: Roman Questions by Plutarch, Vol. IV, Loeb Classical Library 1936.

${ }^{18} \mathrm{H}$. Denzinger, Enchiridion symbolorum definitionum et declarationum de rebus fidei et morum, ed., P. Hünermann, Bologne 1995 nº. 118-119, p. 61.

${ }^{19}$ Ibid., nº. 185, p. 103, no. 711, p. $405, n^{\circ} .1809$, p. 739. 
une espèce de " carte blanche » pour ceux qui voulaient se prévaloir du privilège!)

À partir du XVe siècle, les couples lad'cs ont commencé à jouir d'un assouplissement dans les règles prescrites pour la vie conjugale. La modération et la flexibilité qu'apporteraient la Renaissance et l'Époque de la Lumière (XVII e siècle) auraient des répercussions considérables. Les gens ont commencé à voir le mariage comme un don de Dieu. Ce fut le début du changement à l'enseignement traditionnel de l'Église sur le mariage.

\section{LA NOTION DE L'INFÉRIORITÉ DE LA FEMME}

La notion que la femme est une créature inférieure existait bien avant le christianisme. Pendant de nombreux siècles, avant le Moyen Âge jusqu'au XIXe siècle, les femmes se sont battues pour contrer la notion de leur infériorité, pour obtenir leurs droits et une position sociale égale à celle des hommes. Dans de nombreux pays, les femmes, hormis leur charme naturel, leur intelligence, leurs talents, leur aspect mystérieux, sans oublier leur égalité aux yeux de Dieu, n'avaient aucun droit. (Aujourd'hui encore, dans plusieurs pays, la situation des femmes n'a guère changé.)

$\mathrm{Au}$ Moyen Âge et au temps de la Renaissance, les femmes n'avaient pas accès à l'éducation. D'ailleurs, l'enseignement se faisait par les hommes pour les hommes. En général, ces derniers gardaient et manifestaient une antipathie à l'égard des femmes. Au niveau universitaire, l'enseignement se faisait par des moines, des prętres et des laïcs. La formation masculine donnait une vision du monde qui justifiait la domination des hommes et affermissait leur hégémonie dans plusieurs domaines de la vie et des affaires du monde. En plus, la pensée masculine était imprégnée du concept que les femmes sont la source de tout mal. Elles sont les auteurs du péché. Elles empêchent les hommes de se mériter le Paradis. Elles sont les plus imparfaites de toutes les créatures de Dieu. En 1558, John Knox, prédicateur anglais et auteur de "First Blast of the Trumpet Against Monstrous Regiment of Women ", affirme que la femme, en dépit de sa grande excellence, a été conçue pour obéir aux hommes et les servir. ${ }^{20}$ (On est porté à se demander si, aujourd'hui au XXI ${ }^{\mathrm{e}}$ siècle, cette idée existe toujours dans le subconscient collectif masculin.)

${ }^{20}$ E. Moreau, La Crise religieuse du XVI siècle: Histoire de l'Église, depuis les origines jusqu' à nos jours, Bloud and Gray, Paris 1950, op. cit., p. 433. 
Évidemment, cette perception ne correspond pas à la vision que Dieu a des femmes. Dans l'Évangile, nous voyons que Jésus était cause de scandale. Lui, Le Maître, parlait avec les femmes, un comportement contraire à la loi de cette époque. En se basant sur les évangiles, on peut supposer que dans la communauté des apôtres et des disciples, les femmes aussi étaient présentes. L'une d'elles, Joanna, est mentionnée dans l'évangile de Luc. ${ }^{21}$ Aujourd'hui, on dirait que ces femmes sont des "émancipées » parce qu'elles ne respecteraient pas la tradition en ce qui concerne la conduite propre aux femmes.

À l'époque de Jésus, de façon générale, si une femme adressait la parole à un homme dans la rue, son mari pouvait la renvoyer sans s'acquitter de la dette conjugale. Au contraire, si Le Maître ou son disciple parlait à une femme dans la rue, son attention était considérée une transgression sociale, un affront! Les femmes qui entouraient Jésus n'étaient pas des auditrices passives. Elles échangeaient ouvertement et librement avec Lui. Après sa résurrection, Jésus a choisi de se présenter aux femmes en premier, et non pas aux hommes! Par ce geste, Jésus a valorisé et validé la femme, confirmant son statut social comme étant égal à celui de l'homme. Elles furent les premières à annoncer la résurrection du Christ! " À leur retour du tombeau, elles rapportèrent tout cela aux Onze et à tous les autres. " ${ }^{22}$

La spontanéité de Jésus dans ses rapports avec les femmes frappa męme ses propres disciples. Pendant sa rencontre avec la Samaritaine au puits, Jésus lui demande de Lui donner à boire. L'Évangile nous apprend que, lorsque les disciples arrivèrent, ils s'étonnaient de voir Jésus qui parlait à une femme, et par surcroît, une Samaritaine! (Les Juifs et les Samaritains étaient ennemis.) Pourtant, pas un d'entre eux Lui demanda, «Que cherches-tu? » ou « De quoi lui parles-tu? »23

En étudiant les coutumes et traditions qui ont "obligé » les femmes à travers le monde, avant notre ère, au début du christianisme et jusqu'au XIX ${ }^{e}$ siècle, on peut facilement reconnaître que l'attitude qui veut que les femmes sont des "créatures inférieures ", est une constante. Dans toute cette triste et bouleversante histoire, Jésus a été le seul à les avoir valorisées comme femmes, le seul à les avoir respectées comme personnes humaines. Cette sollicitude singulière pour les femmes, qu'avait Jésus, se fait effectivement très rare au Moyen Âge!

\footnotetext{
${ }^{21}$ Luc 8,3 .

${ }^{22}$ Luc 24,9.

${ }^{23}$ Jean 4,27 .
} 


\section{CONCLUSION}

La période entre les $\mathrm{V}^{\mathrm{e}}-\mathrm{VI}^{\mathrm{e}}$ siècles et le Concile de Trente (1563-1575) est marquée par le silence de l'Église sur la question de la vie conjugale, à l'exception de sa reconnaissance occasionnelle de la légitimité du mariage. Même la contribution magistrale de saint Thomas d'Aquin (1225-1274) n'a pas apporté d'éclaircissements puisque son enseignement était basé essentiellement sur celui de saint Augustin. Il serait juste de dire qu'il n'y a pas eu de progrès véritable dans le domaine de la vie conjugale du couple depuis l'Antiquité, époque régie par la loi romaine.

L'Église était plutôt préoccupée par son expansion territoriale. Mais cette propagation a nécessité une différente façon de penser et de faire les choses, quoique l'infrastructure de l'Église demeura toujours à l'image de celle de l'Empire romain.

Mais, croire que son épanouissement était accompagné de cette même abstraction du mariage serait une erreur. L'histoire de l'Église démontre une réalité tout à fait contraire.

Une conception nouvelle fit son apparition: une dichotomie claire et explicite entre le domaine clerical/spirituel d'une part et le domaine profane/charnel d'autre part. Et cette démarcation dualiste a souligné la supériorité de la virginité et du célibat au dépens de la vie conjugale. Cette catégorisation morale a malheureusement relégué les conjoints à un rang inférieur à celui des personnes dont la vie était formellement consacrée à Dieu. Le mariage est devenu une zone de faiblesses charnelles et de luxure. L'acte sexuel était reconnu et accepté seulement en fonction de sa nécessité pour la procréation. Cette division entre le sacré et le profane au sein de l'Église l'a fait reculer à ses débuts lorsque le christianisme devait se défendre contre le gnosticisme et le manichéisme dont les échos se font toujours entendre dans certaines régions de l'Église catholique. Un fait intéressant: l'Église orthodoxe Elle n'a pas été touchée par ce dualisme parce que ses valeurs sont basées sur celles des Apôtres. Ceux-ci avaient des familles!

Au IV ${ }^{e}$ siècle, le Synode d'Elvira s'est prononcé sur le célibat obligatoire des évêques, des prêtres et des diacres qui devaient s'abstenir de rapports sexuels, męme avec leurs épouses. Cette déclaration a tracé la route pour les futurs synodes qui proposeraient le célibat comme idéal et le décréteraient pour les clercs. Par le Concile de Trente (1545-1563), l'Église a solennellement réaffirmé ses lois essentielles, entre autres, que le célibat était obligatoire pour les prêtres. Le Concile a aussi accordé 
au mariage le statut de sacrement, une attribution d'une importance capitale!

La distinction entre le célibat dans l'Église et le mariage devenu institution, faisait de la prêtrise et du mariage deux entités mutuellement exclusives et presque pas réconciliables, sujettes au Canon de l'Église.

Mais il y avait progrès. Au $\mathrm{XII}^{\mathrm{e}}$ siècle, Abélard expliqua que le plaisir sexuel entre conjoints, de par sa nature, n'était pas péché. Au XIII siècle, la voie vers la sainteté pour les couples fit son apparition, sans que la supériorité de la virginité soit pour autant mise en doute. (Le culte de la Vierge que l'Église conserve est l'une des reliques de l'Antiquité païenne. Par ex. Diane, Myth. rom. Déesse de la Chasse et Nature sauvage, identifiée par les Romains avec l'Artémis hellénique. Le plus célèbre sanctuaire de Diane était dans les monts Albains. Il y avait aussi les vierges Vesta et Minerve (en grec. Athéna).

Il faut reconnaître qu'au Moyen Âge, la vie conjugale et familiale fut écartée en raison de l'accent que l'hiérarchie de l'Église plaçait sur la supériorité de la vie consacrée à Dieu comparée à celle que vivaient la plupart des hommes et des femmes. À cette époque, la question du mariage et de la famille n'était pas une priorité pour l’Église.

\section{LE MARIAGE À L'ÉPOQUE DES LUMIÈRES}

L'une des époques qui apportèrent des changements dans l'histoire de la culture européenne après le Moyen Âge a été la période dite « des Lumières ». "Les Lumières » est le nom donné au mouvement philosophique qui se répand en Europe dès le XVII ${ }^{e}$ siècle et qui domine la pensée européenne au XVIII ${ }^{e}$ siècle jusqu'à la Révolution française. C'est le temps de la découverte de la structure de l'univers et de la nature de l'esprit humain. C'est le temps du rejet de la superstition qui est remplacée par l'observation et l'expérimentation.

L'expression "Les Lumières » vit le jour en Allemagne. Elle s'est répandue dans d'autres régions de l'Europe. L'appellation « Les Lumières » changeait avec la région. En Angleterre, on appela cette période de découverte "L'Âge de la Raison »; en France, "L'Âge de la Philosophie ». Mais le terme générique utilisé dans la littérature pour identifier l'étendue de cette période est «l'Époque des Lumières ».

L'évènement le plus important de cette époque a été la Révolution française. Cette convulsion sociale créa une nouvelle forme de gouverne- 
ment jusqu'alors inconnue dans l'histoire: la république. La république est une structure sociale par laquelle un peuple est gouverné par des représentants librement élus par lui à un parlement. Ce modèle français a inspiré des formes semblables d'administration dans d'autres pays d'Europe. Ce nouvel idéal d'autorité gouvernementale sera adopté en Amérique comme principe fondateur de sa constitution. ${ }^{24}$

\section{L'INSTITUTION DU MARIAGE À LA LUMIÈRE D'UNE NOUVELLE THÉOLOGIE}

L'époque des Lumières introduit un certain assouplissement dans le domaine de la vie conjugale. Sous l'influence de l'époque " des Lumières ", les gens ont commencé à développer une nouvelle vision de l'institution du mariage et de la vie conjugale. Ils ont commencé à s'opposer à l'enseignement de l'Église qui traditionnellement avait placé la virginité et le célibat au-dessus de la vie conjugale. Elle voyait le plaisir d'un mauvais oeil et enjoignait les conjoints de s'en abstenir.

Au début de son pontificat, Jean-Paul II donna une nouvelle vision de la vie conjugale, "la théologie $d u$ corps ». Dès son apparition, elle fournit la base pour une nouvelle vision théologique de la vie de couple. L'Église a essayé de plus en plus de découvrir le mariage tel que révélé dans la Bible. L'Église chercha successivement à mieux comprendre le mariage et à bien préciser sa vision de la vie conjugale.

Autrefois, sous l'influence de certaines philosophies, en particulier celle de la gnose, il y avait tendance à identifier l'aspect physique et matériel de la vie comme étant intrinsèquement imparfait et mal. Cette perception avait un effet sur l'institution du mariage et son élément physique de l'amour. Cette déformation s'insinua dans la doctrine du mariage de l'Église, sans pour autant qu'Elle fasse preuve d'une acceptation universelle à la lumière du vrai christianisme. L'Église croyait que c'était bon que Dieu ait créé le monde matériel et le corps humain. Elle acceptait que tout ce que Dieu avait créé était très bon. ${ }^{25}$

${ }^{24}$ Les États-Unis d'Amérique adoptčrent plusieurs des idées libérales de « L'Âge de Raison »Le programme idéalisant "liberté, égalité, fraternité » que créa la Révolution Française est devenu la base politique et économique dans ce pays.

${ }^{25}$ Cf. Gn 1,31 . 
Une nouvelle vision théologique qu'apporta l'époque « des Lumières " a permis à l'Église de percevoir l'institution du mariage et la vie conjugale selon le dessein de Dieu. Le premier théologien à présenter le mariage dans une nouvelle perspective a été le cardinal Tomas Caje$\tan .{ }^{26} \mathrm{Il}$ reconnut l'importance d'une pleine relation conjugale dans le mariage sans qu'elle soit considérée comme péché, même véniel. Après lui, d'autres théologiens en sont venus à la męme conclusion. Domingo de Soto $^{27}$ et Pierre de Canisius ${ }^{28}$ plaçaient fortement l'accent sur la célébration de l'amour physique et la procréation. Cette nouvelle conception de la vie conjugale a continué tout au long du XVIe siècle. Cette nouvelle vision théologique de la vie de couple donnait l'occasion de formuler un nouvel enseignement officiel de l'Église à l'égard du mariage. En 1679, le pape Innocent $\mathrm{XI}^{\mathrm{e}}$ a déclaré que le plaisir dans la relation conjugale du mariage n'était pas péché. ${ }^{29}$ Cette déclaration servirait dorénavant à une nouvelle perception théologique du mariage par l'Église ${ }^{30}$.

En même temps, le jansénisme ${ }^{31} \mathrm{~s}^{\prime}$ était établi en France. Cette nouvelle vague spirituelle s'en prenait à ceux qui s'opposaient à la doctrine traditionnelle de l'Église en matière de la vie conjugale. Les jansénistes invitaient les couples à pratiquer une morale très sévère dans leur vie conjugale, une discipline telle que proposée par St. Augustin, à savoir que le but unique de l'acte sexuel était la procréation, donc jamais pour le plaisir sexuel. ${ }^{32}$ Le jansénisme dans ce domaine se conformait entièrement aux enseignements de St. Augustin (354-430), de St. Ambroise (340-397), de St. Jérôme (345-419) et de St. Clément d'Alexandrie (150-220).

Il faut souligner que cette nouvelle vision spirituelle que représentait le jansénisme a fait pression sur la pratique religieuse des croyants. La sévérité janséniste allait à l'encontre de la théologie nouvelle qui est apparue dans l'Église durant l'époque «des Lumières ». Antoine

${ }^{26}$ Thomas Cajetan, (son vrai nom Tommaso de Vio), né le 20 février 1469, décédé le 09 aoút 1534 à Ronie; dominicain-italien, cardinal, et théologien.

${ }^{27}$ Domingo de Soto (1494-1560), prętre dominicain, théologien.

${ }^{28}$ Pierre de Canisius, effectivement Pier de Hondt, né le 08 mai 1521 ŕ Nimčgue, décédé en 1597 à Fribourg; théologien jésuite, prédicateur et docteur de l'Église.

${ }^{29}$ Cf. J. Verdon, Le plaisir au Moyen Âge, Paris 1996, p. 76.

${ }^{30}$ Cf. W. Skrzydlewska, Etyka seksualna, p. 15-16.; cf. H. Doms, Du sens et de la fin du mariage, Paris 1937, p. 34-37; cf. K. Wojtyła, Miłość i odpowiedzialność, Lublin 1986, p. 57.

${ }^{31}$ Un mouvement théologique et spirituel fondé par l'évêque d'Ypres, Kornel Otto Jansen (1586-1638).

${ }^{32}$ Cf. P. Adnčs, Le mariage, Paris 1963, p. 132. 
Arnauld ${ }^{33}$ dans une publication intitulée "la sainte communion fréquente ", s'est permis de proposer un régime sexuel pour le couple, avant et après la communion.

Officiellement, les théologiens de l'Église, à l'image de Pline ${ }^{34}$ l'Ancien, un naturaliste du $\mathrm{l}^{\mathrm{er}}$ siècle, ont pris une position plutôt radicale sur l'activité sexuelle des conjoints. Ce dernier avait cité l'éléphant qui ne s'accouple qu'à tous les deux ans, comme exemple de maîtrise de l'impulsion sexuelle et de la fidélité conjugale. Ils recommandaient l'activité sexuelle comme devoir matrimonial. Ils prêchaient la fidélité entre l'homme et la femme dont l'union devait être fixée sur la procréation.... à l'image plinienne de l'éléphant.

Saint François de Sales aussi avait écrit:

«Si lourdaud qu'il soit, cet animal est pourtant le plus digne de tous ceux qui vivent sur la terre, et le plus doué de raison... Il ne change jamais de femelle et aime tendrement celle qu'il s'est choisie et avec laquelle il ne s'accouple pourtant qu'une fois tous les trois ans, pendant une durée de cinq jours et en se cachant si soigneusement que jamais on ne l'aperçoit au cours de cet acte; quand il réapparaît le sixième jour, c'est pour se rendre directement à la rivière oů il se lave tout le corps; il ne regagne pas le troupeau avant de s'être purifié. De telles manières ne sont-elles pas bonnes et droites? $\aleph^{35}$

Dans un recueil de préceptes spirituels, St. François de Sales ajoute une année supplémentaire à l'absence d'activités sexuelles telle que pratiquée par l'éléphant. Cet exemple de maîtrise avait été employé au début du christianisme par les théologiens. Encore aujourd'hui, à certains endroits, l'éléphant est employé comme l'exemple idéal de « contrôle des impulsions » pour les époux.

Pour conclure cette explication plutôt intéressante, il est obligatoire de bien souligner que l'éléphant de Pline, tel que présenté comme mode d'abnégation par plusieurs théologiens ${ }^{36}$ à différentes époques, avait été

${ }^{33}$ Antoine Arnauld (1612-1694), théologien français, docteur de la Sorbonne, l'un des principaux représentants du jansénisme.

${ }^{34}$ Cf. Histoire naturelle, CRA-D, Libraries-édit, Paris 1824, chap. 8,5.

${ }^{35}$ St. François de Sales, Philothea, chap. 3, 39,: Allan Ross, Introduction to the Devout Life, London 1924.

${ }^{36}$ Richard de Saint-Victor (vers 1173); Guillaume Peraldus (1270); (Il est difficile de confirmer les dates exactes). Alain de Lille (1202), dans une somme anonyme du XIIIe sičcle (Codex latinus Monacensis, 22233) : Cf. J. Phillips, Divinity of the Body : Reclaim the Holiness of your physical self, chap. 5, Sexuality and the Sacred, p. 74. 
doté au temps de St. François de Sales, d'une année supplémentaire d'absence d'activités procréatrices!

\section{LE DROIT DU CONTRAT CIVIL DE MARIAGE}

Toutes les grandes religions considèrent la famille comme une association sainte. Mais chacune, selon sa propre loi, permet la séparation du couple dans le mariage lorsqu'un malentendu sérieux survient. Pour les religions, le mariage n'est pas seulement une question de contrat civil.

La plupart des grandes religions qui sont présentes au monde et celles qui ont déjà existé, ont attaché et attachent encore de nos jours une grande importance à l'homme et la femme en tant que personnes individuelles, et à leur association dans le mariage. Certaines d'entre elles ne donnent pas la permission aux conjoints de divorcer. D'autres, le considèrent comme un mal nécessaire ${ }^{37}$.

Le mariage a connu ses origines aux temps anciens. Dans l'ancienne cité de Rome, un mariage n'avait rien en commun avec la religion. Le mariage était surtout une institution selon une coutume traditionnelle. Il dépendait de la volonté de l'homme et de la femme et était basé sur une amitié mutuelle.

Dans les temps anciens, il n'y avait pas de bureau d'enregistrement pour le mariage à l'état civil. À la fin du VIe siècle, l'Église catholique établit le registre matrimonial. Par la suite, les autres religions adoptèrent le même procédé pour le mariage.

Depuis le Concile de Trente, et selon le droit canonique, le prêtre est le témoin officiel d'un mariage. En ce qui concerne la forme ecclésiastique du mariage, l'Église ajoute la publication des bans et l'obligation pour des futurs mariés de célébrer leur mariage dans une église ${ }^{38}$.

Jusqu'au XVIII ${ }^{e}$ siècle, l'Église tient compte des mariages dans le registre matrimonial. Mais, au début de ce même siècle en Europe, le gouvernement institua l'enregistrement laïc. À partir de ce moment, et de cette façon, les prêtres sont devenus des fonctionnaires de l'État. Par exemple: en Angleterre depuis 1653, il y avait déjà une forme de mariage civil. En 1763, le roi Louis XVI de France institua une forme

${ }^{37}$ Cf. L. Kocik, Wzór matżeństwa i rodziny. Od tradycyjnej jedności do wspótczesnych skrajności. Kraków 2002, p. 34-37.

${ }^{38}$ Cf. W. Kuligowski, Miłość na Zachodzie. Historia antropologiczna, Poznań 2004, p. 99. 
de mariage civil. En 1792, une forme de mariage civil fut établie pour tous les citoyens français. En Autriche la loi civile de 1868 et celle de 1875 ont reconnu le mariage civil. Depuis 1875, le mariage civil est la seule forme de mariage en vigueur en Allemagne comme en France. En Pologne, une loi en vigueur depuis 1929, offre la possibilité de choisir entre deux formes: le mariage à caractère religieux ou le mariage civil.

Le mariage civil dans sa forme actuelle en France a été créé par Napoléon Bonaparte. Des modifications législatives dans le Code Civil ${ }^{39}$ (article 165) font que le mariage est célébré publiquement en face d'un fonctionnaire de l'État dans la résidence de l'un des futurs époux. Pendant cette célébration de mariage civil, le fonctionnaire d'État reçoit une déclaration des futurs époux. Il rédige le certificat de mariage et consigne l'information dans un registre de l'État. ${ }^{40}$

Cependant, parce que les communautés protestantes et anglicanes ne reconnaissaient pas l'autorité de l'Église catholique, les gouvernements ont donné aux futurs époux le droit d'obtenir un contrat de mariage civil. Cette décision a eu deux suivis comme conséquence: le premier a été d'apporter des précisions à la loi civile telle que décrétée par Napoléon en ce qui a trait à la succession. L'introduction de ces changements officiels a permis l'acquisition de droits pour les femmes et les enfants et l'assurance de leur protection. Un testament garantissant officiellement un support à la succession après la mort du mari est devenu de rigueur. Le deuxième suivi s'est manifesté par une sécularisation qui s'est répandue partout en Europe après la Révolution Française. Elle a diminué l'autorité de l'Église dans plusieurs pays, comme en Allemagne de 1871 à 1878.

Dans cette histoire de la sécularisation en Europe, il est intéressant de noter qu'en Israël, ${ }^{41}$ un pays laïc, la question de l'état civil du mariage est laissée dans les mains d'un tribunal rabbinique (tribunal religieux). L'introduction du mariage civil par le gouvernement en plusieurs pays a probablement contribué à l'affaiblissement graduel de la vision

${ }^{39}$ Le Code Civil des Français, appelé usuellement (C.Civ. ou CC) ou aussi Code Napoléon, regroupe les lois relatives au droit civil français. Promulgué le 21 mars 1804, par Napoléon Bonaparte, le Code Civil constitue le statut personnel des citoyens français, de leurs familles et de leurs relations, excepté pour les Français habitants de Moyotte, de la Nouvelle-Calédonie et de Wallis-et-Futuna.

${ }^{40}$ C.Civ., Chp. III, Des actes de mariage, art. 63.

${ }^{41}$ Voir. D. Sibony, Judad'sme et sexualité, Esprit du temps, Paris 2002. 
du mariage telle que préconisée initialement par l'Église. L'innovation qu'a été le mariage civil a donc créé une division entre l'Église et l'État. ${ }^{42}$

\section{LE DIVORCE MATRIMONIAL}

Une autre cause de l'approfondissement de la rupture entre l'État et l'Église a été la décision par l'État de permettre le divorce civil.

Dans la culture occidentale jusqu'au XVI ${ }^{e}$ siècle, le mariage était une union sacramentelle indissoluble. En 1532, le pape refusa d'annuler le mariage du roi d'Angleterre, Henri VIII avec Catherine d'Aragon (précédemment mariée à son frère Arthur). Le refus provoqua une séparation de l'Église catholique et le début de l'Église anglicane. ${ }^{43}$ L'époque post Moyen Âge et celle de la Révolution Française ont mené à l'émergence du droit de divorce. Le divorce fut officiellement introduit en France en 1792, mais son règne a été de courte durée. Après la chute de Napoléon Bonaparte, le catholicisme est devenu la religion de l'État et le droit au divorce fut annulé jusqu'en 1884. Après cette date, le divorce fut restauré. Mais il convient de noter que la position de l'Église catholique sur le divorce n'avait pas changé. Pendant longtemps, l'Église a continué à faire pression sur le droit civil.

\section{L'ANNULATION DU SACREMENT DE MARIAGE}

La loi canonique de l'Église sur le mariage permet l'annulation au tout début d'un mariage. ${ }^{44}$ Le mariage est si important aux yeux

\footnotetext{
${ }^{42}$ Voir. Pie IX, Catalogue des Erreurs Modernes, chap. VII-VIII, Rome 1864.

${ }^{43}$ Voir. C. Erickson, Henryk VIII. Warszawa 2001; A.F. Pollard, Henryk VIII, Warszawa 1979; D. Starkey, Królowe. Sześć żon Henryka VIII, Poznań 2004.

${ }^{44}$ Can. $1061-\S 1$. Le mariage valide entre baptisés est appelé conclu, seulement s'il n'a pas été consommé; conclu et consommé, si les conjoints ont posé entre eux, de manière humaine, l'acte conjugal apte de soi à la génération auquel le mariage est ordonné par sa nature et par lequel les époux deviennent une seule chair. § 2 . Une fois le mariage célébré, si les conjoints ont cohabité, la consommation est présumée, jusqu'à preuve du contraire. §3. Le mariage invalide est appelé putatif, s'il a été célébré de bonne foi au moins par une des parties, jusqu'à ce que les deux parties aient acquis la certitude de sa nullité. Can. $1062-\S 1$. La promesse de mariage unilatérale ou bilatérale appelée fiançailles, est régie par le droit particulier établi par la conférence des Évêques en tenant compte des coutumes et des lois civiles, s'il en existe. $\S 2$. La promesse de mariage ne donne pas lieu à une action pour exiger la célébration du mariage; mais elle peut donner lieu à une action en réparation de dommages, pour autant qu'elle soit due.
} 
de l'Église qu'il ne peut être effectué que par une union sacramentelle. Selon les enseignements et la tradition de l'Église catholique, le mariage est indissoluble, c'est-à-dire qu'il ne peut être terminé que par la mort d'un conjoint.

Toutefois, le Droit Canonique a dû transiger sur la question suivante: À quel moment le sacrement de mariage devient-il insoluble? À l'époque de Benoît XIV (milieu du XVIII ${ }^{e}$ siècle), il était compris que le mariage devenait insoluble à partir du premier acte conjugal.

Le Droit Canonique a bien expliqué que, si toutes les conditions concernant la validité du mariage n'étaient pas remplies, une déclaration de nullité par le tribunal de l'Église était possible ${ }^{45}$.

\section{LE CONSENTEMENT MATRIMONIAL}

Les protagonistes d'une alliance matrimoniale sont un homme et une femme baptisé-e-s, libres de contracter le mariage et qui expriment librement leur consentement. "Etre libre » veut dire : ne pas subir de contraintes, ne pas être empęché par une loi naturelle ou ecclésiastique.

L'Église considère l'échange des consentements entre les époux comme l'élément indispensable "qui fait le mariage. ${ }^{46} \mathrm{Si}$ le consentement manque, il n'y a pas de mariage.

Le consentement consiste en un "acte humain par lequel les époux se donnent et se reçoivent mutuellement $»: 47$ "Je te prends comme ma femme; je te prends comme mon mari. $\gg^{48}$ Ce consentement mutuel des époux s'accomplit quand les deux "deviennent une seule chair. $»^{49}$

Le consentement doit être un acte de la volonté de chacun des contractants, libre de violence ou de crainte grave externe..$^{50}$ Aucun pouvoir humain ne peut se substituer à ce consentement. Si cette liberté manque, le mariage est invalide.Pour cette raison «ou pour d'autres raisons qui rendent nul et non avenu le mariage ", ${ }^{51}$ l'Église peut, après examen de la situation par le tribunal ecclésiastique compétent, déclarer " la nullité

\footnotetext{
${ }^{45}$ Cf. Code de Droit Canonique, les empechements dirimants en général (Can.1073,1082).

${ }^{46}$ Cf. Can. 1057.

${ }^{47}$ Cf. Can. 1057.

${ }^{48}$ Cf. Rituel du mariage, p. 45.

${ }^{49}$ Marc 10,8.

${ }^{50}$ Éph 5,31; cf. Can. 1103.

${ }^{51}$ Cf. Can. 1095-1107.
} 
du mariage ", ${ }^{52}$ c'est-à-dire que le mariage n'a jamais existé. En ce cas, les contractants sont libres de se marier, quitte à se tenir aux obligations naturelles de l'union antérieure.

\section{CONCLUSION}

D'autres périodes ont succédé à celle du Moyen Âge et dans l'évolution de l'humanité elles ont progressivement marqué la civilisation. Et ces vagues successives amenèrent des changements qui ont exercé une grande influence sur le mariage et la famille.

Depuis le XVIII ${ }^{\mathrm{e}}$ siècle, la philosophie et la science ont placé l'homme à la tęte de la création. Malheureusement, cette distinction a eu comme conséquence négative la dépréciation de la religion et de la spiritualité. La liberté prime dans les domaines de la vie sociale, matrimoniale et familiale. Les valeurs et le comportement sont secoués par le raz de marée de l'affranchissement et de la liberté. On mettra l'accent sur le caractère humain du mariage.

Dans l'Église, certains théologiens critiquaient la vision augustinienne et thomiste de la vie conjugale. Et cette critique plutôt sérieuse a fait suite à celle de Hugues de Saint-Victor (XII ${ }^{\text {e }}$ siècle) puis Sanchez et Basil Ponce de Léon (XVII ${ }^{e}$ siècle) qui avaient prêché que l'élément le plus important dans le mariage était l'amour. Mais les obstacles théologiques et culturels firent que le progrès a connu un certain retardement.

À la fin du XVIII ${ }^{\mathrm{e}}$ siècle, et au début du XIX ${ }^{\mathrm{e}}$ siècle, les théologiens, surtout les théologiens allemands, annoncèrent que le principal objectif du mariage n'était pas la procréation et l'éducation des enfants, mais la création par les conjoints d'une communauté spirituelle basée sur leur amour.

Grâce à la Révolution Industrielle, les femmes, (souvent des mères de famille) ont quitté la maison pour le marché du travail, pour des raisons financières. Elles ont goûté l'indépendance. Cette libération a brisé les barrières traditionnelles et contribué à l'affaiblissement de la famille. Le travail, l'accès à l'éducation et aux professions et la participation à part égale à la vie sociale, ont eu un grand impact sur les relations entre l'homme et la femme. Cette situation a conduit à l'élaboration d'un nouveau modèle de mariage et une nouvelle définition des relations

\footnotetext{
${ }^{52}$ Cf. Can. 1071.
} 
sans engagements et responsabilités. Ce modèle est devenu populaire, presque conventionnel. Pour cette raison, un décalage fit son apparition entre l'amour et les responsabilités qu'on y associe. Dans bien des cas, l'amour est devenu synonyme du plaisir.

La venue de la psychologie comme science humaine a permis une meilleure compréhension de l'humain, surtout dans son quotidien, incluant le mariage et la famille. La psychologie fit la lumière sur les causes profondes du comportement individuel et cet accent sur l'individualisme a contribué au fractionnement du mariage et de la famille.

L'Église s'est très difficilement adaptée à ces grands bouleversements sociaux. Depuis la seconde moitié du XIX ${ }^{\mathrm{e}}$ siècle, l'Église se penche plus sérieusement sur la question épineuse du mariage et de la famille. Cette réévaluation atteindra son point culminant au Concile Vatican II et, par la suite, dans l'enseignement du Pape Jean-Paul II.

\section{EWOLUCJA INSTYTUCJI MAŁŻEŃSTWA A KOŚCIÓł KATOLICKI POZYCJA MAtŻEŃSTWA W ŚREDNIOWIECZU}

\section{STRESZCZENIE}

Rozwój myśli teologicznej w średniowieczu i poglądów św. Augustyna pozwoliły sprecyzować wizję małżeństwa w aspekcie etyki seksualnej. Według zapoczątkowanej w pierwszych wiekach przez Ojców Kościoła, wizji małżeństwa oraz ich spojrzenia na istotę aktu małżeńskiego, współżycie małżonków nadal było traktowane jako grzech, jeśli nie służyło prokreacji. Podchodzono do tej kwestii z wielką niechęcią, uciekając się nawet do wulgarnych określeń.

W tym okresie, wymogi, które stawiał Kościól, spotykały się z dezaprobatą ze strony wiernych. Chrześcijanie lekceważąco traktowali nauczanie Kościoła dotyczące pożycia małżeńskiego. Skoro każdy akt seksualny w małżeństwie poza prokreacją stanowił grzech więc małżonkowie nie przejmowali się wiernością małżeńską ani wstrzemięźliwością seksualną zalecaną przez Kościół. W związku z tym Kościół podejmuje próby skodyfikowania problemu pożycia małżeńskiego, poddając go ścisłej reglamentacji. Obowiązującymi dniami wstrzemięźliwości seksualnej stały się następujące dni: sobota, niedziela, każdy dzień świąteczny oraz środy i piątki w Wielkim Poście i Adwencie.

Według nauczania Kościoła tamtych czasów, pary małżeńskie, nie przestrzegające nakazanej wstrzemięźliwości mogły spodziewać się narodzin dzieci niepełnosprawnych: epileptycznych, trędowatych czy wręcz nienormalnych. Cytat z kazania Cezarego z Arles: „Trędowaci rodzą się zazwyczaj nie z mądrych rodziców, którzy zachowują czystość w stosownych dniach, a przede wszystkim z prostaków, którzy niezdolni są zapanować nad sobą". 
W średniowiecznych klasztorach począwszy od VI wieku powstawały swoiste katalogi grzechów i pokut, szczególne miejsce poświęcono nadużyciom w sferze seksualnej. Oto fragment niemieckiego kanonika, Burcharda z Wormacji, który w XI wieku pisał w swoim liście o nadużyciach małżonków: „Czy z twą małżonką bądź z jakąkolwiek kobietą, spółkowałeś od tyłu, na modę psów Jeśli to uczyniłeś, odbędziesz pokutę dziesięć dni o chlebie i wodzie“. Dalej: „Czy obcowałeś z twoją małżonką gdy jawnie już stało się poczęcie. Jeśli to uczyniłeś, odprawisz pokutę dziesięciu dni o chlebie i wodzie. [...] Czy zbrukałeś się ze swoją małżonką w Wielkim Poście musisz pokutować przez czterdzieści dni o chlebie i wodzie albo złożysz dwadzieścia sześć soldów jałmużny. [...] Jeśli zdarzyło się to, gdy byłeś pijany, będziesz odbywał pokutę dwadzieścia dni o chlebie wodzie".

Opracowane przez Ojców Kościoła nowe spojrzenie na instytucję małżeństwa i uzupełnione przez św. Augustyna było kontynuowane przez teologów Kościoła w okresie średniowiecza. Wywyższono wówczas bezżeństwo i abstynęcję seksualną ponad instytucję małżeństwa. Utorowało to drogę do sukcesywnego wprowadzenia etapami celibatu księży w Kościele zachodnim. Pierwszym ważnym krokiem w tej dziedzinie był kanon trzydziesty trzeci, ustanowiony podczas hiszpańskiego synodu w Elwirze, na początku IV wieku. Nakazywał on osobom duchownym żyjącym w związkach małżeńskich powstrzymanie się od pożycia i prokreacji. Konsekwencją naruszania tego zakazku było wykluczenie ze stanu duchownego. Nie chodziło tu zatem jeszcze o celibat $\mathrm{w}$ ścisłym tego słowa znaczeniu. Na tym etapie nie wymagano jeszcze bezżenności księży, niemniej jednak ten zakaz był pierwszym krokiem na długiej drodze reform zmierzających do wprowadzenia celibatu.

Papież Innocenty II, na Soborze Laterańskim w 1139 roku objął klauzulą nieważności wszystkie małżeństwa zawarte tajnie już po przyjęciu święceń kapłańskich. Od tej pory zawarcie małżeństwa i przyjęcie kapłaństwa zaczęły się prawnie wykluczać. Od 1139 roku zakazano księżom zawarcie związków małżeńskich, a od soboru trydenckiego uniemożliwiono przyjmowanie święceń kapłańskich osobom żonatym.

Sytuacja zmieniała się bardzo powoli i opornie. Rozpoczęty w XI wieku wielki ruch reformatorski w Kościele dążył do schrystianizowania małżeństwa, czyniąc z niego instytucję religijną, w końcu nadając jej rangę sakramentu. W XII wieku Piotr Abelard głosił odważnie: „Nie można nazywać grzechem naturalnej przyjemności ani też mówiąc o winie, gdy ktoś cieszy się przyjemnością, od której odczuwania nie może się powstrzymać. Bowiem od pierwszego dnia naszego stworzenia, gdy człowiek żył jeszcze bezgrzesznie w Raju, stosunkom małżeńskim i kosztowaniu wybornych potraw zawsze towarzyszyły przyjemności“.

W XIII wieku w pewnym stopniu można powiedzieć, że następuje częściowa jakby rehabilitacja instytucji małżeństwa, bo otwiera się dla niej droga do świętości, lecz nadal wyklucza się sprawę pożycia małżeńskiego. Kościół zaleca małżonkom dążącym do świętości, aby po przyjściu dziecka na świat, zaniechali aktywności seksualnej. Idąc za poglądami św. Augustyna, Kościół określił dla małżeństwa dwa cele: spłodzenia potomstw i wychowanie dzieci zgodnie ze starotestamentalnym 
nakazem Boga: „Bądzcie płodni i rozmnażajcie się“ oraz „ dla uniknięcia rozpusty zgodnie z wypowiedzią św. Pawła“ (1 Kor 7).

W czasach poapostolskich promowanie dziewictwa nigdy nie zostało poddane wątpliwościom. Biograf św. Julianny pisze: „Szczęśliwa dziewica. Nim zbrukały ją doczesne pieszczoty, poślubiona została Chrystusowi poprzez swą miłość“. Po dziś dzień pozostajemy w obrębie tych pojęć. Czystość w symbolicznym znaczeniu nadal pozostaje synonimem abstynencji seksualnej.

Przełom XIV i XV wieku przyniósł pewne rozluźnienie w kwestii pożycia małżeńskiego. Pod wpływem poglądów oświecenia ludzie zaczeli postrzegać wartość małżeństwa jako dar dany od Boga. Zaczęto sprzeciwiać się tradycyjnemu nauczaniu Kościoła, jego podejściu do spraw pożycia małżeńskiego.

Kajetan, ówczesny kardynał, oficjalnie wypowiedział się, iż każdy stosunek małżeński, nawet jeśli nie służy prokreacji, w jego przekonaniu nie jest żadnym grzechem. Ten właśnie pogląd, o zabarwieniu nieco liberalnym, przetrwał przez cały XVI wiek. Wybitni teologowie tacy jak, Dominik de Soto czy Piotr Kanizjusz, wręcz dowartościowywali miłość fizyczną i uważali, że wcale nie musi ona służyć wyłącznie prokreacji. Natomiast oficjalne stanowisko Kościoła w tym zakresie nie ulega zmianie. Konsekwentnie umniejszanie wartości miłości fizycznej i przekładanie dziewictwa i abstynencji seksualnej nad instytucję małżeństwa sprawiło w konsekwencji, że coraz większą rolę w Kościele zaczął odgrywać celibat. 